\title{
The Role of Magnetic Resonance Imaging in the Evaluation of Children with Cerebral Palsy: A Proton Magnetic Resonance Spectroscopy Study
}

\author{
RANIA S. ABOUKHADRAH, M.D.; NOHA M. ABD EL-MABOUD, M.D. and \\ AL-SHYMAA ZAKREYA AL-SHAHAWY, M.D. \\ The Department of Radio-Diagnosis and Medical Imaging, Faculty of Medicine, Tanta University, Tanta, Egypt
}

\begin{abstract}
Background: Study of brain metabolites using 1 HMRS in children with cerebral palsy.

Aim of Work: To study the metabolite changes in the basal ganglia of children with CP in comparison with a normal control group of the same age by using proton magnetic resonance spectroscopy (1HMRS).

Material and Methods: Thirty children with different types of CP with associated developmental delay were examined. Different types of CP were included (spastic, dyskinetic, dystonic or choreo-athetoid and ataxic CP). The control group consisted of twenty normally developing children. The relative concentrations of $\mathrm{N}$-acetylaspartate (NAA), choline (Cho), myo-inositol $(\mathrm{mI})$, creatine $(\mathrm{Cr})$ and their combinations within $1 \mathrm{~cm}$ brain multi voxels were measured.

Results: Children with CP showed reduced ratios of NAA: $\mathrm{Cr}$, NAA: Cho, $\mathrm{mI}$ : $\mathrm{Cr}$ in the basal ganglia and the increased ratio of NAA: $\mathrm{mI}$ and $\mathrm{CHO}: \mathrm{CR}$ in relation to that of the control group. There was age-dependency increase in NAA: $\mathrm{Cr}$ and NAA: Cho in the basal ganglia. Metabolites ratio differs according to the severity of CP.

Conclusion: MRS plays a promising role in evaluating children with cerebral palsy and also in determining the degree of learning disability aiming at a better rehabilitation of children with $\mathrm{CP}$.
\end{abstract}

Key Words: Cerebral palsy - MRS - Basal ganglia.

\section{Introduction}

CEREBRAL Palsy (CP) is a non-progressive motor disorder due to a defect or lesion in the developing brain. Learning disability, sensory disturbance and epilepsy are common problems in CP [1] . CP results from an insult to the brain likely cerebral cortex, cortico-spinal tract and the basal ganglia. The clinical signs of $\mathrm{CP}$ differs according

Correspondence to: Dr. Rania S. Aboukhadrah,

The Department of Radio-Diagnosis and Medical Imaging, Faculty of Medicine, Tanta University, Tanta, Egypt to the affected brain area [2]. Neuroimaging of children with CP helps determining the etiology of $\mathrm{CP}$ whether it is metabolic or genetic and also aids in a better prognosis [3].

Conventional Magnetic Resonance (MR) imaging plays an important role in detecting brain lesions in patients with CP [4]. These brain lesions range from white matter injuries (periventricular leukomalacia, ventricular dilatation and porencephalic cyst), grey matter injuries (brain atrophy) and other congenital brain malformation [5]. While the conventional MRI study is the best imaging technique in detection the cause of $\mathrm{CP}$, many $\mathrm{CP}$ cases appear normal in conventional MRI, in this cases, the functional MRI plays important role in detecting the change in the brain function, even with no obvious gross conventional MR changes [4] . Proton magnetic resonance spectroscopy (1HMRS) is a safe, non-invasive method for the measurement of the brain metabolites [6]. 1HMRS was performed in the basal ganglia of children with $\mathrm{CP}$ and revealed a reduction in the $\mathrm{NAA} / \mathrm{Cr}$, Cho/Cr, NAA and Cho in the basal ganglia $[1,7]$ The aim of our work is to study the metabolite changes in the basal ganglia of children with $\mathrm{CP}$ in comparison with a normal control group of the same age.

\section{Patients and Methods}

The study protocol was approved by the local Ethics Committee and a written informed consent was obtained from the parents of each child, the present study done at Radio-Diagnosis and Imaging Department, Tanta University Hospital from January 2016 to March 2018. It included 30 children with different types of CP (18 males, 12 females; 
mean age 4y) were referred from Neuropediatric Department. Twenty three children had spastic CP, three children dyskinetic $\mathrm{CP}$, two had mixed $\mathrm{CP}$ and two ataxic CP. Twenty normal children of the same age served as control group (Table 1) and were free from neurological or psychiatric disorders and had normal conventional brain MRI. Seven children had a normal intelligence, 23 had mild to moderate learning disability (children with a severe learning disability were excluded from the study). Prenatal history was acquired from all children; 12 children had a history of incubation and prematurity less than 37 weeks, and 18 children were born at full term. Children with severe disabilities were excluded. Our study involved children with a normal brain MRI, those with abnormal brain findings (cortical abnormalities, white matter abnormality) were excluded.

Table (1): Clinical data of children with spastic Cerebral Palsy (CP) and control group.

\begin{tabular}{lll}
\hline Data & $\begin{array}{c}\mathrm{CP} \\
(\mathrm{N}: 30)\end{array}$ & $\begin{array}{c}\text { Control group } \\
(\mathrm{N}: 20)\end{array}$ \\
\hline Age: Mean & $1-7 \mathrm{y}$ & $1-9 \mathrm{y}$ \\
Sex: & & \\
$\quad$ Males & 18 & 15 \\
$\quad$ Females & 12 & 5 \\
Gestational age: & & \\
$\quad$ Full term & 12 & 19 \\
$\quad<37$ weeks & 10 & 1 \\
Birth weight: & & 2 \\
$\quad$ Low birth weight $(<2500 \mathrm{~g})$ & 5 & 18 \\
$\quad$ Normal birth weight & 25 & \\
\hline
\end{tabular}

All examinations were performed using a 1.5 T MR Unit (SIGNA Horizon, General Electric Medical System, Milwaukee, WI), the head coil was used and the child who required a sedative was given chloral ( $1 \mathrm{ml}-\mathrm{kg})$. All children were examined by axial T1 WI (TR/TE: 400-600/10-20 $\mathrm{m} / \mathrm{sec}$.), axial T2 WI (TR/TE: 2000-4000/100-120 $\mathrm{m} / \mathrm{sec}$.), coronal and axial FLAIR (TR/TE/TI:4000$6000 / 140 / 1200 \mathrm{~m} / \mathrm{sec}$.), the slice thickness was $5 \mathrm{~mm}$, the matrix was $256 \times 256$ and the field of view was $220-240 \mathrm{~mm}$., 1HMRS two voxels were placed on the basal ganglia bilaterally with a voxel size $(1 \mathrm{X} 1 \mathrm{X} 1 \mathrm{~cm})$ on axial cuts of normally appearing brain with TR: 4880, TE: 98.5 and 5mm section thickening, MRS was done for evaluating the following metabolites obtained at the following concentrations (in parts/million): NAA at $2.01 ; \mathrm{Cr}$ at 3.0; Cho at 3.22; $\mathrm{mI}$ at 3.55. The peak area metabolite ratios (NAA: Cr, NAA: Cho, NAA: mI, Cho: $\mathrm{Cr}, \mathrm{mI}$ : $\mathrm{Cr}$ ) were calculated. The total study time ranged from 30 to 45 minutes.

\section{Statistical analysis:}

Statistical analysis was undertaken to prove the efficacy of MRS of the basal ganglia in the evaluation of CP. Statistical analysis was performed using the SPSS software package Version 16.0 (statistical package for social science TM) and $p<0.05$ was considered to be statistically significant. The sensitivity and specificity for each protocol was compared in order to evaluate the reliability of MRS.

\section{Results}

Thirty children with $\mathrm{CP}$ and normal conventional MRI were examined. All the twenty ND children had normal MRI. No differences of the metabolite ratios between the right and left basal ganglia were noted in both groups (Table 2).

No gender difference was detected in the studied metabolites in children with CP (e.g. NAA/Cho in males $=1.268, p=0.965$; in females $=1.276, p=0.758$ ). Also, no gender difference was found in the control group for all tested metabolite ratios (e.g. NAA/ Cho in males $1.845, p=0.158$; in females 1.721 , $p=0.198$ ). An age-dependent increase of the ratios of NAA/Cr and NAA/Cho in the basal ganglia of children with $\mathrm{CP}$ were found $(p<0.001$; and $p<0.01$ respectively). Similar results were obtained for $\mathrm{NAA} / \mathrm{Cr}$ and NAA/Cho in the control group $(p<0.001$; and $p<0.01$ respectively).

A decreased ratio of NAA/Cr and NAA/ Cho ratios in the basal ganglia of $\mathrm{CP}$ children $(p<0.01)$.

The reduced ratio of NAA/CR, NAA/CHO, $\mathrm{Cho} / \mathrm{Cr}$ and NAA/Mi in both basal ganglia of children with CP Figs. (1-4) and control group differed significantly (Table 2 ).

However, no significant difference in the $\mathrm{Mi} / \mathrm{Cr}$ ratio in the children with $\mathrm{CP}$ in comparison with the control group was found, the NAA/Mi ratio was increased in more sever cases.

Table (2): Comparison between the metabolites ratio in the basal ganglia of both $\mathrm{CP}$ and control group.

\begin{tabular}{lccccc}
\hline \multirow{2}{*}{ Ratio } & \multicolumn{2}{c}{ Control group } & \multicolumn{2}{c}{ CP } & $\begin{array}{c}p- \\
\text { value }\end{array}$ \\
\cline { 2 - 5 } & Rt (sd) & Lt (sd) & Rt (sd) & Lt (sd) & \\
\hline NAA/CR & $1.94(0.20)$ & $1.98(0.23)$ & $1.53(0.29)$ & $1.15(0.25)$ & 0.001 \\
NAA/CH & $2.22(0.25)$ & $2.27(0.21)$ & $1.26(0.26)$ & $1.29(0.23)$ & 0.012 \\
NAA/MI & $3.84(0.61)$ & $3.68(0.68)$ & $8.47(2.73)$ & $8.50(2.26)$ & 0.10 \\
CH/CR & $0.95(0.07)$ & $0.93(0.05)$ & $1.21(0.19)$ & $1.19(0.20)$ & 0.005 \\
MI/CR & $0.52(0.15)$ & $0.58(0.11)$ & $0.19(0.9)$ & $0.18(0.8)$ & nd \\
\hline
\end{tabular}

Nd: Non-significant. 


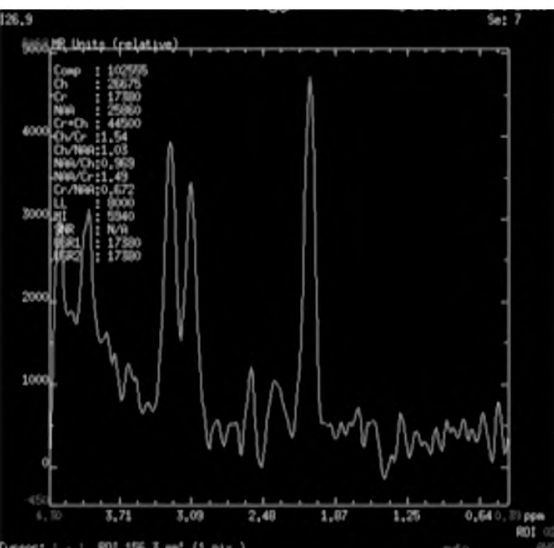

(A)

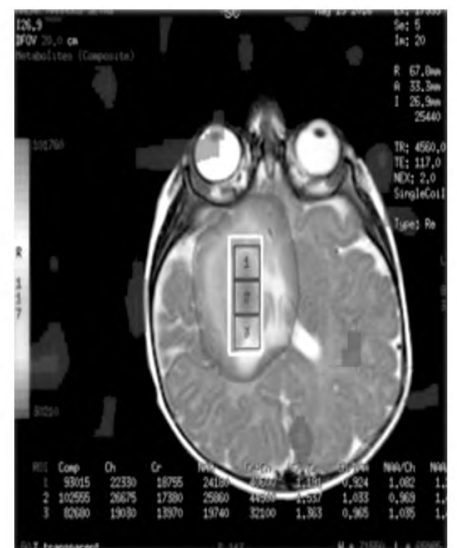

(B)

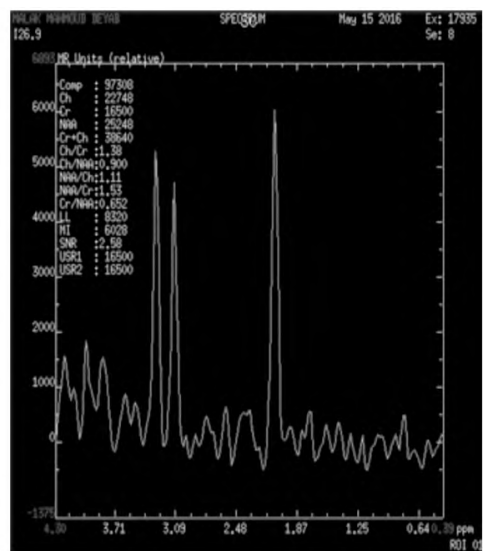

(C)

Fig. (1): A female child aged 10 months with clinical CP MRS voxels on both right (1A,1B) and left ganglia (2) show reduced level of NAA/CR, NAA/CH, $\mathrm{CH} / \mathrm{CR}$ and $\mathrm{MI} / \mathrm{CR}$ relative to comparison group.

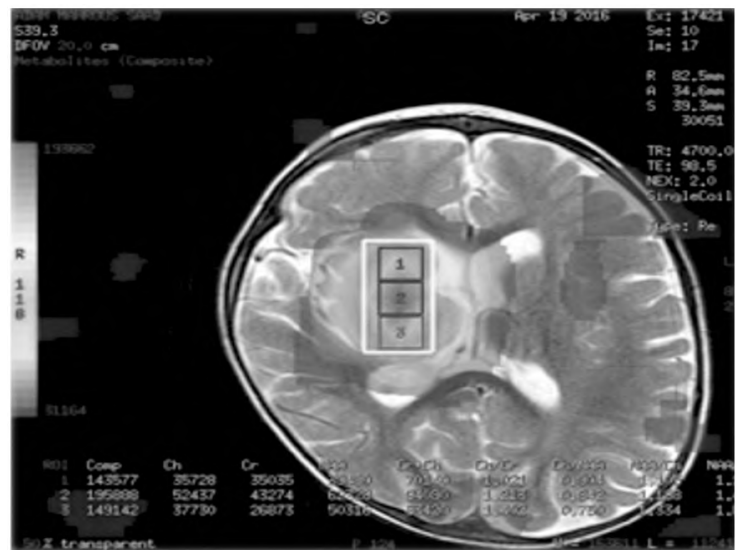

(A)

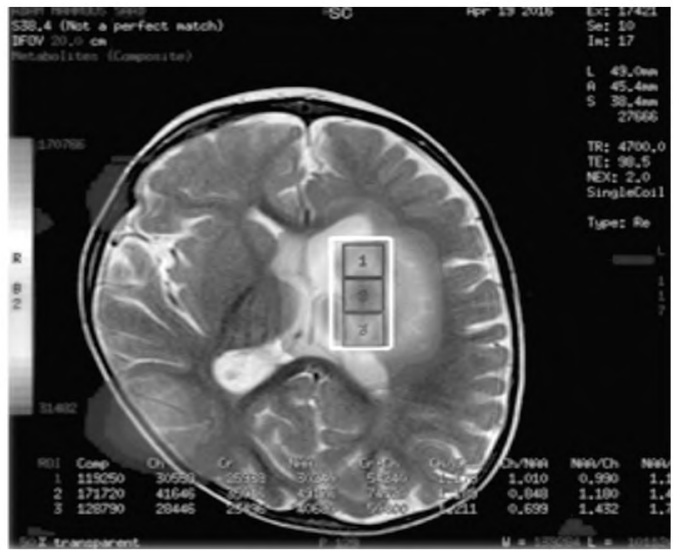

(C)

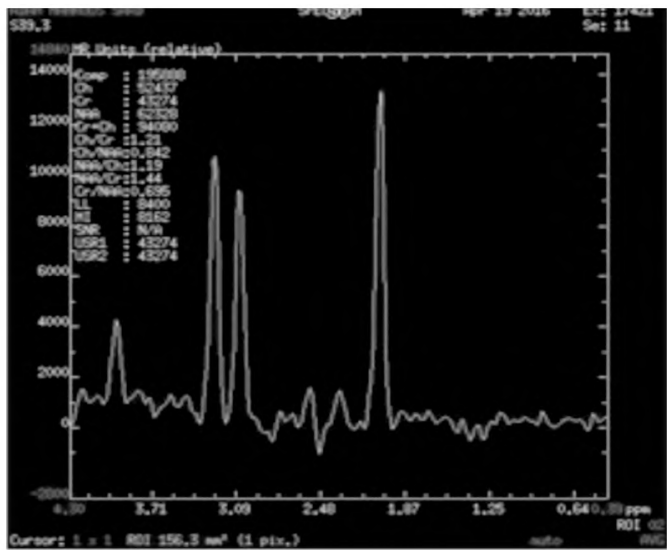

(B)

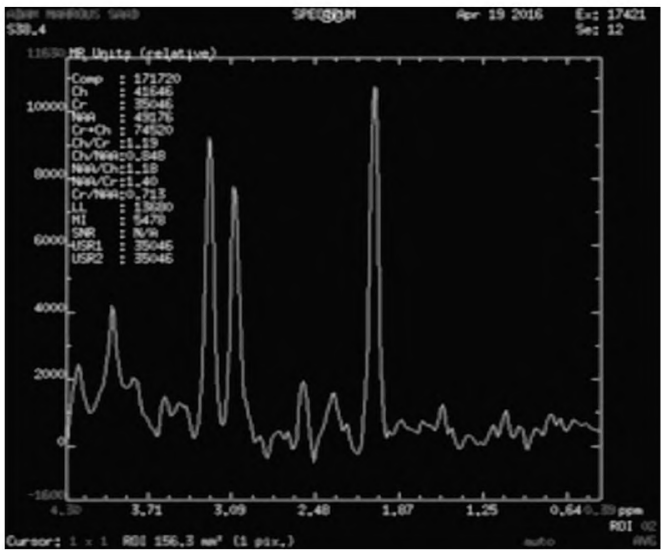

(D)

Fig. (2): Male child aged 3 years and diagnosed clinically to be spastic CP with conventional MRI picture mild peripheral atrophic changes and MRS on both basal ganglia (right: $2 \mathrm{~A}, \mathrm{~B}$ ) and left basal ganglia (2C,D) show reduced level of NAA/CR, NAA/CH, $\mathrm{CH} / \mathrm{CR}$ and $\mathrm{MI} / \mathrm{CR}$ ratio relative to comparison control group. 

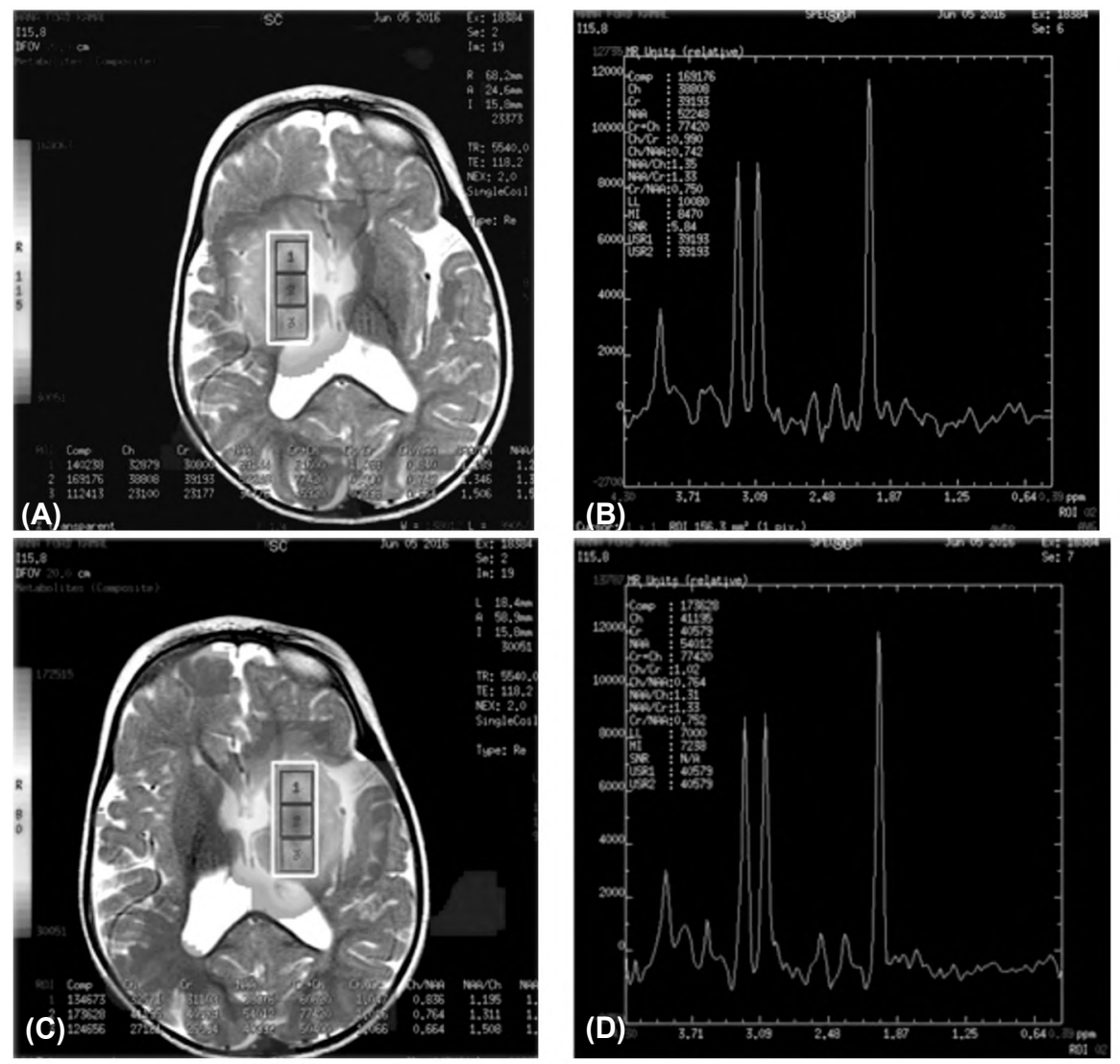

Fig. (3): Female child aged 4 years diagnosed with atonic $\mathrm{CP}$ with peripheral atrophic brain changes on conventional MRI, on both basal ganglia right side $(4 A, B)$ and left side (4C,D) show reduced level of NAA/CR, NAA/CH, $\mathrm{CH} / \mathrm{CR}$ and $\mathrm{MI} / \mathrm{CR}$ ratio relative to comparison control group.
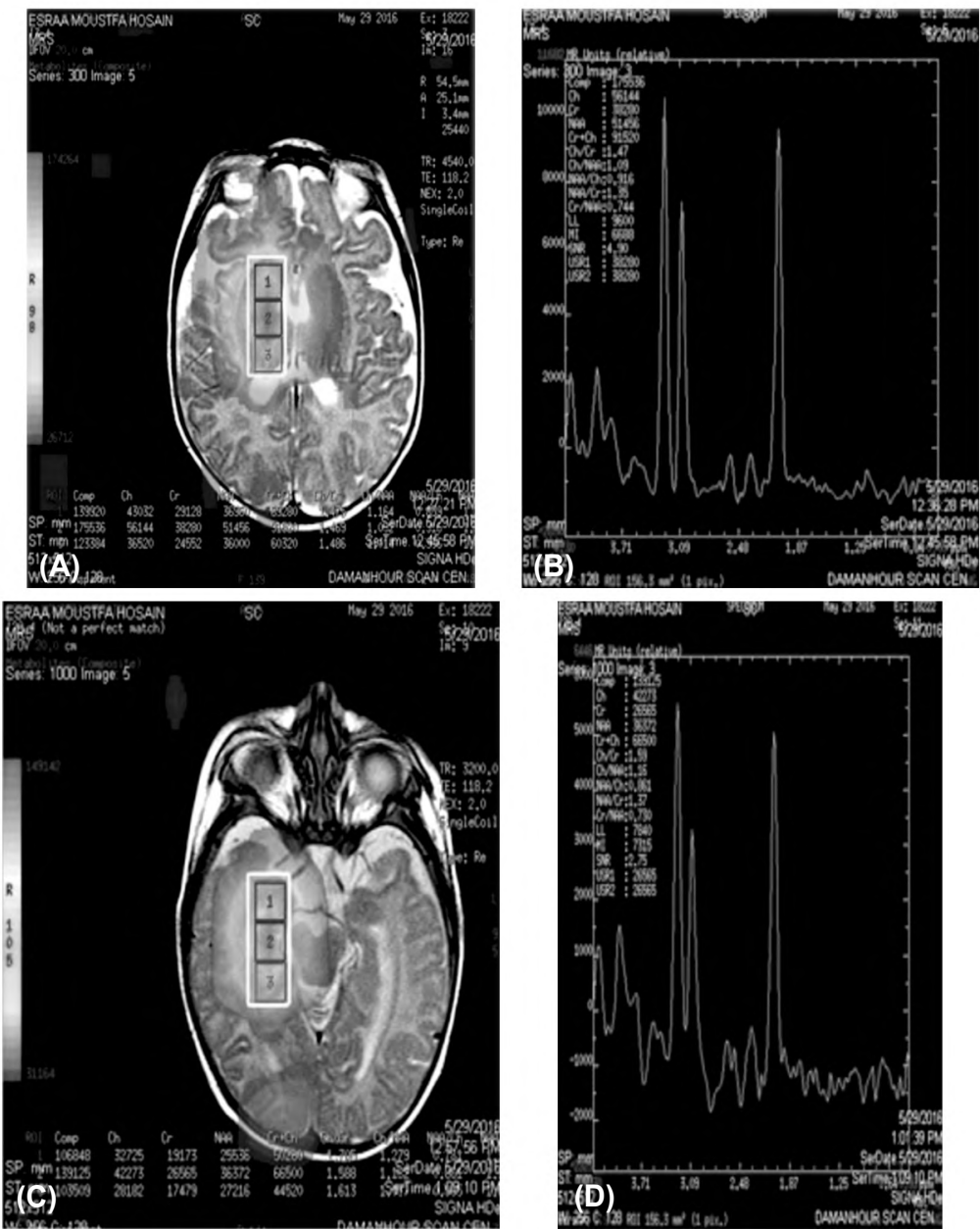

Fig. (4): Female child aged 11 months diagnosed clinically to be CP convention MRS were done on both basal ganglia right side (4A,B) left $(4 \mathrm{C}, \mathrm{D})$ shovel of NAA/CR, NAA/CH, $\mathrm{CH} / \mathrm{CR}$ and $\mathrm{MI} / \mathrm{CR}$ relative to comparison group. 


\section{Discussion}

For many years conventional MRI was the best imaging moralities in the imaging of the brain of $\mathrm{CP}$ children. It can assess the anatomical and morphological changes in the brain in the form of atrophic changes, PVL, multiple white matter infractions and other anatomical changes, but there are many $\mathrm{CP}$ children with normal MRI brain and show different features of CP. The promising techniques such as MRS will help in the detection of changes that occur at the cellular level even with no morphological changes and this will help in a better evaluation of $\mathrm{CP}$ children will help in more understanding of the brain changes in the child with $\mathrm{CP}$ and thus better assessment and rehabilitation is possible [8].

The water content of the infant's brain is higher than that of the adult's brain, but it decreases over the first few months of life. The NAA level and NAA/Cr ratio increase with cerebral maturation. The Cho/Cr ratio is higher in infants than in adults, but it declines slowly until the age of 2 years [9] The most sensitive brain metabolite is NAA which is present in all neuronal cells and any neuronal damage or loss results in a decrease in its level [10].

The present study included 30 children with different types of CP and a control group of 20 children. We measure the metabolites level in both basal ganglia (the primary structure to maturate and myelination occurs early in the perinatal period and continues over the first two years of life; so, early changes in the brain structures affect the basal ganglia first [8]

No significant left/right basal ganglia metabolite ratio differences were noted for any metabolite ratios in children with $\mathrm{CP}$ and in those of the control group, which coincide with the study of Kulak et al., [1].

In our study we observed that there was no significant gender difference for all tested metabolites in both normal and CP children, and these findings are in agreement with Kulak et al., [1], Pouwels et al., [11]. However, Kadota et al., [12] found relatively small gender differences, and Kulak et al., [13] found gender differences in the control group but not in $\mathrm{CP}$ group.

Our result also showed an age-dependent increase in the NAA/Cr, NAA/Cr that may be due to progressive brain maturation and myelination and this positively matched with the result of Kulak et al., [11], Flippi et al., [1], and Kulak et al., [13] who assumed that the NAA/Cr and $\mathrm{Cho} / \mathrm{Cr}$ ratios have a significant age-dependent increase in the basal ganglia, but was higher in healthy children.

The normal brain function mainly depends on the NAA and by monitoring its level we can assess brain function as we found that there is a significant reduction in the NAA, Cho, $\mathrm{Cr} \& \mathrm{mI}$, which coincide with the study of Auvichayapat et al., [6] Kulak \& Sobaniec [14] stated that there was a reduction in NAA, Cho $\& \mathrm{mI}$ as a result of the neuronal loss, but there was an increase in the $\mathrm{Cr}$ ratio which reflects an increase in the metabolism of the basal ganglia.

Our study showed a reduction in the NAA/ Cho, NAA/Cr, NAA/mI compared to the control group, this was in agreement with Kulak et al., [13] \& Kendall et al., [1 $\mathbf{r}$ who assumed that the NAA/ Cho, NAA/Cr and NAA/mI reduced in both basal ganglia of $\mathrm{CP}$ children.

The NAA/Cr \& NAA ratios were found to have a relation with the learning disability in patients with $\mathrm{CP}$ as we found that this ratio tends to decrease in the basal ganglia of children with learning problems and this matched with the result of Kulak et al., [11] \& Hashimoto [8].

The NAA $/ \mathrm{mI}$ ratio was increased in more severe cases; this coincides with Kulak et al., [6]

\section{Conclusion:}

The metabolites of the brain of $\mathrm{CP}$ children are significantly different from the normal child and this may help in an early detection and rehabilitation of $\mathrm{CP}$ children.

\section{References}

1- KULAK W., SOBANIEC W., SMIGIELSKA-KUZIA J., et al.: Metabolite profile in the basal ganglia of children with cerebral palsy: A proton magnetic resonance spectroscopy study. Developmental Medicine \& Child Neurology, 48: 285-9, 2006.

2- NORTON N.S. : Cerebral palsy. X Pharm: The comprehensive pharmacology reference, 1-5, 2007.

3- KULAK W. and SOBANIEC W.: Cerebral palsy in children in northeastern Poland. J. Pediatr. Neurol., 2: 79-84, 2004.

4- BARKOVICH A.J., BARANSKI K., VIGNERON D., et al.: Proton MR spectroscopy for the evaluation of brain injury in asphyxiated, term neonates. Am. J. Neuroradiol., 20: 1399-405, 1999.

5- KULAK W., SOBANIEC W., GOSCIK M., et al.: Clinical and neuroimaging profile of congenital brain malformation in children with spastic cerebral palsy. Adv. Med. Sci., 53: 42-8, 2008.

6- AUVICHAYAPAT P., AREE-UEA B., AUVICHAYAPAT N., et al.: Transient changes in brain metabolites 
after transcranial direct current stimulation in spastic cerebral palsy: A pilot study. Frontiers in Neurology, 366: $1-9,2017$.

7- KRÄGELOH-MANN I., HELBER A., MADER I., et al.: Bilateral lesions of the thalamus and basal ganglia: Origin and outcome. Dev. Med. Child. Neurol., 44 (7): 477-84, 2002.

8- HASHIMOTO T., TAYAMA M., MIYAZAKI M., et al.: Developmental brain changes investigated with proton magnetic resonance spectroscopy. Dev. Med. Child Neurol., 37: 398-405, 1995.

9- FILIPPI C.G., ULUG A.M., DECK M.D.F., et al.: Developmental delay in children: Assessment with proton MR spectroscopy. A.J.N.R., 23: 882-8, 2002.

10- NOVOTNY E., ASHWAL S. and SHEVELL M.: Proton magnetic resonance spectroscopy: An emerging technology in pediatric neurology research. Pediatr. Res., 44: 1-10, 1998.

11- POUWELS P.J., BROCKMANN K., KRUSE B., et al.:
Regional age dependence of human brain metabolites from infancy to adulthood as detected by quantitative localized proton MRS. Pediatr. Res., 46: 474-85, 1999.

12- KADOTA T., HORINOUCHI T. and KURODA C.: Development and aging of the cerebrum: Assessment with proton MR Spectroscopy. Am. J. Neuroradiol., 22: 12835, 2001.

13- KULAK W., SOBANIEC W., SMIGIELSKA-KUZIA J., et al.: An age and gender dependency of metabolite concentrations in basal ganglia in children with spastic diplegia: Proton magnetic resonance spectroscopy study. J. Child. Neurol., 24: 73-9, 2009.

14- KULAK W. and SOBANIEC W.: Proton magnetic resonance spectroscopy (1 H-MRS) in children with spastic diplegia. Developmental Medicine \& Child Neurology, 46: 287-8, 2004.

15- KENDALL G.S., MELBOURNE A. and JOHNSON S.: White matter NAA/Cho and Cho/Cr ratios at MR Spectroscopy are predictive of motor outcome in preterm infants. Radiology, 271: 230-8, 2014.

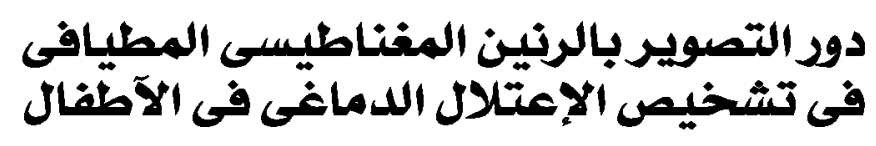

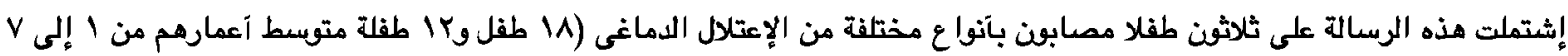

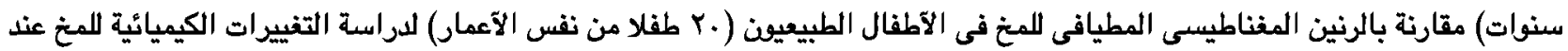
هؤلاء الآطفال.

$$
\begin{aligned}
& \text { خضع كل المرضى للفحص الإكلينيكى متضمنا التاريخ المرضى وتاريخ ما قبل الولادة وما بعدها. } \\
& \text { قمنا بلراسة مستوى تركيز الان استيل اسبرتات وكولين وميوانيسيتول وكيراتين ونسبتهم فى الفوكسل الواحد وقد وجدنا آن نسب هذه }
\end{aligned}
$$

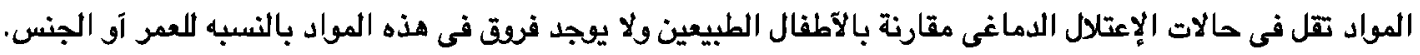

$$
\begin{aligned}
& \text { إيجازا فإن التصوير بالرنين المفناطيسى المطيافى يلعب دورا هاما في تثخيص الإعتلال الدماغى فى الآطفال. }
\end{aligned}
$$

